\title{
A dimensão espacial e o lugar social da loucura: por uma cidade aberta
}

\author{
The spatial dimension and the social place of madness: \\ for an open city
}

Leticia Paladino (https://orcid.org/0000-0001-7151-7689) ${ }^{1}$

Paulo Duarte de Carvalho Amarante (https://orcid.org/0000-0001-6778-2834) ${ }^{1}$
${ }^{1}$ Laboratório de Estudos e Pesquisas em Saúde Mental e Atenção Psicossocial, Escola Nacional de Saúde Pública Sergio Arouca, Fundação Oswaldo Cruz. R. Leopoldo Bulhões 1480 Manguinhos. 21041-210 Rio de Janeiro RJ Brasil. leticiapaladino@gmail.com
Abstract The Brazilian Psychiatric Reform (BPR) process proposes a break with the asylum paradigm in several dimensions. Thinking about care spaces and the right to the city are important flags for this issue. Bearing that in mind, a theoretical-conceptual framework was constructed, aiming to discuss and systematize the relationship between the architecture of care spaces geared toward madness and the production of subjectivities and relationships. Thus, based on archeo-genealogy, a dialogue was organized between concepts and authors that approach space and architecture as devices for the production of subjectivities and relationships, such as total institutions and self-mortification (Erving Goffman) and space-behavioral syndrome (Mirian de Carvalho), as well as experiences such as those by Maura Lopes Cançado and Lima Barreto. It is also the aim of this study to discuss and draw, through the lens of different fields of knowledge, an ideal city that will aid in facing the asylum paradigm and strengthening the BPR process: the open city, that which includes difference. Locating the importance of discussing the architectures, spaces, and the city built for the BPR process, this article proposes to build and add a new dimension of analysis of such a process to those that already exist: the spatial dimension.

Key words Cities, Architecture, Mental health, Healthcare reform
Resumo $O$ processo de Reforma Psiquiátrica Brasileira (RPB) propõe o rompimento com o paradigma manicomial em diversas dimensões. Pensar nos espaços de cuidado e no direito à cidade constituem bandeiras importantes para tal. Dessa forma, construímos um arcabouço teórico-conceitual objetivando discutir e sistematizar a relação da arquitetura dos espaços de cuidado destinados à loucura e à produção de subjetividades e relações. Assim, a partir da arqueogenealogia, organizamos um diálogo entre conceitos e autores que abordem o espaço e a arquitetura como dispositivos de produção de subjetividades e relações, tais como, instituições totais e mortificação do eu (Erving Goffman) e sindrome espaço-comportamental (Mirian de Carvalho), e experiências como as de Maura Lopes Cançado e Lima Barreto. Objetivamos, ainda, discutir e desenhar, pelas lentes de campos diversos de saber, um ideal de cidade que nos ajude a enfrentar o paradigma manicomial e fortalecer o processo de RPB: a cidade aberta, aquela que inclui a diferença. Ao localizarmos a importância da discussão das arquiteturas, dos espaços e da cidade que construímos para o processo de RPB, propomos, como resultado deste artigo, construir e adicionar uma nova dimensão de análise de tal processo às já existentes: a dimensão espacial.

Palavras-chave Cidades, Arquitetura hospitalar, Saúde mental, Reforma dos serviços de saúde 


\section{Introdução}

\section{A loucura entre espaços e tecnologias de poder}

Como nos mostra Foucault ${ }^{1}$, a loucura é uma construção social imersa em um discurso de poder. A arquitetura, enquanto campo, e suas expressões espaciais também fazem parte desse discurso ou seja, produzem relações de poder que sustentam um determinado paradigma. Ao longo da história europeia-ocidental esses dois discursos andaram juntos e foram sofrendo mudanças. $\mathrm{O}$ período de transformação mais importante desses dois discursos e de suas associações encontrase na Modernidade. A loucura vista pelos olhos da psiquiatria moderna nascente é a ruptura do sujeito com a razão e é no enclausuramento que se vislumbra um meio de recuperá-la. Através do dispositivo arquitetônico do manicômio, a loucura ganhou um novo lugar no imaginário social ao mesmo tempo que um novo lugar na cidade. Ficando relegado a essa peça específica do território na cidade, o louco vai sendo forçado a ocupar esse lugar como um lugar natural de sua existência.

Os manicômios são, para Venturini², um espaço de internamento que priva o sujeito de autonomia, com uma arquitetura onde há “(...) uma convergência de múltiplas intenções que querem encarcerar, separar um dentro e um fora, erigir barreiras (...)" (p. 119). A cidade moderna é concebida para ser ampla, organizada e bela, colocando às margens (ou dentro das barreiras) da cidade tudo e todos que não correspondam ou atrapalhem esses ideais. As cidades como objeto de intervenção da medicina e a própria medicalização da loucura estruturaram o terreno propício para que diferentes problemas sociais fossem enquadrados como loucura e afastados da cidade rumo aos manicômios ${ }^{3}$.

Essa dinâmica entre loucura, enclausuramento e exclusão da cidade sofreu modificações e ajustes, mas a tática do enclausuramento não foi posta em questão até o pós-Segunda Guerra Mundial em meados do século XX. Esse tensionamento entre o paradigma psiquiátrico que veio sendo construído ao longo da sociedade moderna e esse novo paradigma que tenta rompê-lo, começa nos países que estavam no centro desta guerra, mas o movimento se espalha e alcança o Brasil na década de 1970. Um país em efervescência política, em meio a ditadura cívico-militar, mas que encontrava seus espaços para pensar a Reforma Sanitária e um Movimento de Reforma Psiquiátrica.
Enquanto a Reforma Sanitária propunha uma ruptura com o modelo da História Natural da Doença e defendia que saúde-doença era de fato um processo com determinantes sociais e por isso um direito da sociedade e um dever do Estado 4 , a Reforma Psiquiátrica Brasileira (RPB) propunha o deslocamento do olhar da loucura para o sujeito que a experiencia. Assim, no final da década de 1970 e início da de 1980, o Brasil tem no cerne da sua reconstrução democrática e dos movimentos que emergem nesse período o sujeito cidadão. Cidadão esse que tem direito à cidade. Tão importante quanto pleitear esse direito à cidade para os loucos - tanto aqueles egressos de longa internação quanto aqueles que ainda terão experiências com a loucura - é entender que cidade, que espaços de cuidado dentro da cidade e que tipo de ocupação da cidade queremos promover ao longo do processo de RPB. Afinal, qual a importância dos espaços de cuidado? Qual o papel que as arquiteturas desses espaços desempenham? Seriam eles capazes de produzir e propiciar subjetividades específicas, como o sujeito-cidadão ou o sujeito-sujeitado? Qual é o papel que a cidade desempenha nisso tudo? Que proposta de cidade, que acolha as diferentes experiências subjetivas, podemos construir ao longo da RPB?

É com a proposição de construir um arcabouço teórico-conceitual que nos ajude a pensar e analisar essas questões ao longo do processo de RPB que o artigo teve como objetivos discutir e sistematizar a relação da arquitetura dos espaços - aqui especificamente os destinados à loucura - com a produção de subjetividades e relações, assim como objetivou construir, a partir de uma discussão teórica, um ideal de cidade que nos ajude a enfrentar o paradigma manicomial e fortaleça o processo de RPB. Dessa forma, a partir da arqueogenealogia, organizamos um diálogo entre conceitos e autores que abordem o espaço e a arquitetura como dispositivos de produção de subjetividades e relações e, posteriormente, exploramos, a partir de diversos campos, concepções de cidade.

Ao longo dos anos de estudo, tornou-se claro que abordar a questão dos espaços, arquiteturas e discussão de cidade no processo de RPB é, além de um desafio, necessário e relevante à medida que dá centralidade a uma temática que comumente habita a periferia das discussões. Tal processo, sendo entendido como um processo social complexo ${ }^{5}$ que, portanto, é vivo, dinâmico, perpassa diferentes âmbitos e deve estar sempre sendo analisado, deveria dar centralidade à dis- 
cussão arquitetural e espacial como um dos pilares de superação do paradigma manicomial. Assim, surge como um desdobramento orgânico ao longo da construção do trabalho, a proposta de adicionar uma nova dimensão às dimensões já existentes e propostas por Amarante ${ }^{6,7}$ para analisar o processo de RPB: a dimensão espacial.

\section{Espaços produzindo subjetividades e relações}

Iniciaremos a construção do arcabouço teórico acerca dos espaços, arquiteturas e produção de subjetividades e relações através do espaço mais extremo da experiência-arquitetural: as instituições totais, dentre elas, os manicômios. Erving Goffman, quando foi realizar o seu trabalho de campo entre 1955 e 1956 no Hospital St. Elizabeths, uma instituição federal com pouco mais de sete mil internos em Washington D.C, objetivava primordialmente abordar o mundo do interno e a sua vivência. Ou seja, ele queria conhecer o mundo social do internado e de como ele o vivia, experienciava-o. Desse trabalho de campo surge Manicômios, prisões e conventos em que Goffman ${ }^{8}$ logo nos lembra de um aspecto da nossa sociedade moderna: o de exercer diversas atividades, tais como, dormir, brincar e trabalhar, em diferentes lugares, com diferentes coparticipantes e sob diferentes autoridades. Às instituições que transgridem essas barreiras que separam essas três esferas da vida são caracterizadas por ele como instituições totais. Assim, o autor diz que

Uma instituição total pode ser definida como um local de residência e trabalho onde um grande número de indivíduos com situação semelhante, separados da sociedade mais ampla por considerável periodo de tempo, levam uma vida fechada e formalmente administrada ${ }^{8}$ (p. 11).

Uma das características das instituições totais é o seu caráter de "fechamento" ao mundo social, impondo barreiras, inclusive físicas (muros altos e portas fechadas, por exemplo), que impedem a relação do interno com o mundo exterior. Tais instituições são destinadas àqueles que a sociedade entende como inúteis ou representantes de uma certa ameaça à comunidade, por isso as prisões, mas também os manicômios. Em ditas instituições, as pessoas que nela ficam internadas, passam por um processo de subjetivação denominado mortificação do $\mathrm{eu}^{8}$.

Fui internada no IP. Minha primeira impressão foi de pânico. Abriram-me uma porta, vi-me diretamente no refeitório. As mesas cinzentas de pedra, algumas doentes despenteadas, com os cabelos em pé, fizeram-me recuar. Uma enfermeira segurou-me pelo braço: “- Não pode mais sair." Trocaram meu vestido pelo uniforme, puseram-me no pátio. Só o cinema será capaz de mostrar o que é o $I P^{9}$ (p. 195).

Ao falar a partir da sua própria experiência por internações em Institutos Psiquiátricos em Minas Gerais e no Rio de Janeiro entre o final dos anos de 1940 e 1950, Cançado ${ }^{9}$ relata um processo de perda de identidade que ocorre em instituições totais. Tal processo acompanha o interno desde a primeira vez que adentra a instituição. Assim, tiram dela o seu vestido, obrigando-a a usar outra roupa, ou melhor, o mesmo uniforme que todos os outros internos e proferem a sentença: "Não pode mais sair".

Nas instituições totais é comum, já na admissão, o interno iniciar o processo de mortifcação do eu ao ser obrigado a trocar suas roupas por um uniforme da instituição, ao ganhar um número de identificação, ao perder o direito de possuir objetos pessoais e de ter um espaço próprio, ao perder o direito de comer a hora e o que quiser, ao perder o direito de tomar banho a hora que quiser, ao perder o direito de dormir quando quiser, ao perder o direito de transitar por onde quiser e quando quiser, enfim, um eu mortificado.

O grau de interferência dessas instituições totais na vida e no cotidiano dos internos é tão expressivo que, por mais que todos nós construamos nos espaços em que habitamos os nossos próprios "espaços pessoais"10, o grau de interferência se faz tamanho que os espaços pessoais são invadidos ou coibidos de existir - como no caso da proibição de objetos pessoais ou a determinação de realizar certas tarefas em momentos pré-estabelecidos. O espaço pessoal tal qual define Sommer ${ }^{10}$, seria ao mesmo tempo um território portátil, afinal, podemos leva-lo para onde formos, e também seria “(...) uma área com limites invisíveis que cercam o corpo das pessoas, e na qual os estranhos não podem entrar"10 (p. 32).

Um dos horrores de qualquer reclusão é nunca se poder estar só. No meio daquela multidão, há sempre um que nos vem falar isto ou aquilo. No Hospício eu ressenti esse incômodo que só pode ser compreendido por quem já se viu recolhido a qualquer prisão; lá, porém, é pior do que em outra qualquer (... $)^{11}$ (p. 166).

Lima Barreto esteve internado no Hospício Nacional de Alienados, na Praia Vermelha, em internações entre os anos de 1910 e início de 1920. O sentimento que Lima Barreto transpõe para o papel, faz-nos lembrar que aquilo que parece simples e básico em nossas relações pode simplesmente ser ignorado ao adentrar essas insti- 
tuições. O território do eu é violado, ou seja, “(...) a fronteira que o indivíduo estabelece entre seu ser e o ambiente é invadida e as encarnações do eu são

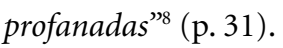

Contemporâneo de Goffman, Russell Barton, psiquiatra estadunidense que atuava em Hospitais Psiquiátricos, cunhou, a partir de observações e estudos do próprio ambiente de trabalho, o termo neurose institucional. A escolha pelo termo neurose reflete a sua formação em psiquiatria (à época embasada nas estruturas da psicanálise) ao mesmo tempo que demarca o objetivo do autor que é o de compreender a neurose institucional como uma doença. Esta, apesar de não ter uma única causa certa e definida, é associada com alguns fatores do ambiente, dentre eles, a arquitetura em que o interno vive e se caracteriza pelos seguintes sintomas: apatia, falta de iniciativa, perda de interesse, falta de expressão de sentimentos e falta de interesse no futuro. Às vezes, toda essa apatia dá lugar a episódios pontuais de agressão que, normalmente, são atribuídos à "doença mental." ${ }^{12}$

Se observarmos, constataremos que há uma proximidade entre os sintomas da neurose institucional e alguns sintomas classificados como psiquiátricos. Assim, ao caracterizá-los como sintomas que ocorrem em consequência de uma vivência em um hospital psiquiátrico, deslocamos a ideia de recaída do interno para algo produzido dentro da própria instituição. Apesar de nos distanciarmos de Barton em alguns momentos de sua categorização, principalmente no que se refere a trata-la como doença, o que colocaria o interno sob mais uma camada do poder médico, esse deslocamento se apresenta como um avanço na questão.

Franco Basaglia, em uma Comunicação no I Congresso Internacional de Psiquiatria Social em Londres quando era diretor do hospital psiquiátrico em Gorizia, no ano de 1964, retoma Barton para falar dos efeitos da neurose institucional.

Assim, quando o doente entra no asilo, alienado pela enfermidade, pela perda das relações pessoais com o outro e, portanto, pela perda de si mesmo, em vez de encontrar ali um lugar onde possa libertar-se das imposições dos outros sobre si e reconstruir seu mundo pessoal, depara-se com novas regras que impelem a objetificar-se cada vez mais, até identificar-se com ela ${ }^{13}$ (p. 25).

O que Basaglia está defendendo é a impossibilidade de um tratamento em uma instituição com as características asilares. Nesse momento ele ainda acreditava que era possível uma certa reforma e transformação desses espaços em Co- munidades Terapêuticas, o que na experiência de Trieste torna-se inviável. Logo, seria necessário acabar com o hospital psiquiátrico. Mas em 1964 ele falava do sistema de "porta aberta", um espaço sem grade, sem portões, o que daria “(...) ao doente a percepção de estar vivendo num lugar de tratamento onde pode conquistar gradativamente a sua relação com os 'outros', com quem cuida dele, com seus companheiros"13 (p. 31). A mesma pergunta que rondará a cabeça de Basaglia nos anos seguintes é a que fazemos agora: é possível produzir um cuidado antimanicomial em uma instituição com características asilares?

Essa pergunta que cercava os pensamentos de Basaglia parece estar ainda nos dias atuais nos pensamentos de muitos militantes, teóricos e profissionais do campo. Uma dessas pessoas é Mirian de Carvalho, doutora em Filosofia que desenvolveu pesquisas com arquitetos do Programa de Pós-Graduação em Arquitetura da Universidade Federal do Rio de Janeiro sobre os problemas pertencentes à relação entre ambiente construído e comportamento espacial. Partindo da hipótese de que o espaço construído interfere no comportamento dos que transitam nele, Carvalho $^{14}$ realizou observação participante em instituições psiquiátricas. Um dos desdobramentos dessa pesquisa aponta para uma interferência significativa desses espaços no comportamento dos usuários das instituições, no que ela vai denominar de sindrome espaço-comportamental.

Um eu mortificado é aquele que não habita o espaço da instituição e sim, apenas nela mora. Afinal, ao contrário do espaço de moradia, "no espaço habitável o indivíduo faz escolhas, modifica o ambiente, podendo sair e entrar livremente (...)"15 (p. 126). Os manicômios, como uma instituição total, por concepção, são constituídos para que eles modifiquem os sujeitos, enquanto que o contrário é interditado. As normas ditas ou não-ditas que fazem parte dessas instituições e atravessam a vida dos internos são capazes de produzir "respostas comportamentais relacionadas com espaços mal projetados"16 (p. 322).

A imbricação entre loucura e arquitetura faz com que seja urgente trabalhar os espaços que destinamos ao cuidado daqueles que estão em sofrimento psíquico, por isso, "(...) a doença mental torna-se um observatório indispensável para o arquiteto e para quem quer analisar criticamente a perda progressiva do tecido social e dos espaços experimentados pela cidade" ${ }^{17}$ (p. 57). Carvalho $o^{14}$ alerta para a importância de se realizar estudos no âmbito do processo da RPB por considerar que a crescente implantação de 
serviços substitutivos deve garantir os preceitos deste processo. Acreditamos que esses estudos colaborariam com o desenvolvimento de estratégias e políticas que rompessem com a lógica manicomial e tivessem no seu âmago a ocupação da cidade.

\section{Por uma cidade onde desconhecidos se encontrem}

Foucault ${ }^{18}$ nos faz pensar, no espaço enquanto expressão das tecnologias de poder e que, portanto, dá-se em um certo contexto, não sendo uma simples expressão de uma época. Esta premissa também é defendida pela socióloga francesa $\mathrm{Ma}-$ rion Segaud que trabalha com a interseção entre sociologia, antropologia e arquitetura. A autora afirma "que o espaço não é uma noção homogênea, mensurável, existente $a$ priori, independentemente das culturas, dos tempos históricos e das representações que uns e outros fazem dela"19 ( $\mathrm{p}$. 20-21). Nessa perspectiva antropológica considera-se que a relação do indivíduo e do grupo com o espaço corrobora com a identidade de cada um. Assim, a pedagogia do espaço é a forma de entender os espaços como instrumentos de saber e poder, que possuem uma eficácia social que é frequente na nossa sociedade ao mesmo tempo que pode ser problemática.

Quando no século XVIII a arquitetura sofre uma especialização enquanto campo que se articula com as questões da sociedade - saúde e urbanismo -, percebemos um deslocamento do foco do poder da figura soberana para as pessoas, para os seus corpos e para os seus cotidianos. Com isso, a arquitetura passa a incidir nos espaços que permeiam a vida, tais como a casa, a escola e o hospital. A arquitetura torna-se "a arte que determina e articula o espaço"20 (p. 6), afinal, a "arquitetura é, antes de mais nada, construção; mas, construção concebida com o propósito primordial de ordenar e organizar o espaço para determinada finalidade e com determinada intenção"21 (p. 246). O que presenciamos é a associação entre o poder disciplinar e o biopoder, articulação que no Brasil começa a ocorrer fortemente no século XIX. Nesta relação, as técnicas disciplinares funcionam como um instrumento de regulação da vida e de normalização dela, pois o biopoder como "um poder que tem a tarefa de se encarregar da vida terá necessidade de mecanismos contínuos, reguladores e corretivos" ${ }^{\prime 22}$ ( $\mathrm{p}$. 134). É essa mesma relação ou associação entre os poderes que encontramos tanto nos espaços específicos destinados ao controle e à normatiza- ção daqueles que são considerados loucos como no controle e na normatização da cidade que habitam.

A loucura no Brasil nem sempre foi a loucura do manicômio. Esse processo é produzido pari passu com a expansão e transformação das grandes cidades em cidades modernas baseadas nos ideais burgueses. E é em nome desses ideais que "bairros inteiros passam a ser desapropriados e demolidos, empurrando para a periferia as classes pobres e minorias, em privilégio de uma

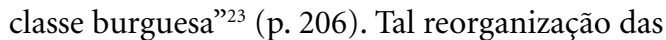
grandes cidades no Brasil ocorre no século XIX após a chegada da Família Real com o objetivo de transformá-las aos moldes das grandes metrópoles europeias. Assim, o saber médico desempenha um papel fundamental na normatização das cidades, transformando-as em um espaço de atuação de suas práticas e, em consequência, transformando a sociedade em seu objeto de intervenção $0^{3}$. É neste contexto, que diferentes párias sociais são enquadradas como "desarrazoados" e empurrados para os manicômios que também ficavam nas periferias da "cidade moderna bela e organizada" em uma dinâmica de medicalização da loucura, que configurava uma questão social e higienista capturada pelo interesse científico e o discurso do progresso ${ }^{24}$.

Ao longo desse processo de medicalização e exclusão da loucura da cidade, foram diferentes os espaços ocupados pelos loucos - embora a finalidade de segregação perpassasse todos eles. Assim, desde a inauguração do Hospício de Pedro II em 1852 foram inaugurados, até 1886, mais oito estabelecimentos iguais a esse nas grandes cidades brasileiras. O tempo passava, os hospícios lotavam e o poder médico ganhava cada vez mais centralidade. O advento da República traz novas transformações nas cidades brasileiras e o Rio de Janeiro, como capital, passará por mais uma transformação urbana. Em 1902, na presidência de Rodrigues Alves e no governo do prefeito Francisco Pereira Passos, são iniciadas grandes reformas urbanas e de saneamento. Novamente tentando se equiparar às cidades europeias com suas grandes avenidas, despejou-se, sem nenhuma compensação financeira, moradores dos cortiços da região central e portuária com o pretexto de reestruturação. Na sua grande maioria, os moradores da região eram negros, desempregados e pobres que não cabiam mais nessa nova cidade. As Colônias ganhavam, assim, novos candidatos. Nos anos seguintes a criação de Colônias se amplia e se espalha para outras cidades da República. Sabemos onde esse processo 
nos levará: às superlotações, a incontáveis infringimentos dos direitos humanos, a iatrogenias, à segregação extrema, enfim, às barbacenas.

A Reforma Psiquiátrica Brasileira, deflagrada nos anos 1970 por profissionais, usuários e familiares, acadêmicos e membros da sociedade civil, instaurou um processo de transformação em diversos âmbitos e instâncias com inspiração em outras experiências de Reformas Psiquiátricas pelo mundo visando a superação do paradigma manicomial. Uma das estratégias para essa superação era a ocupação e a retomada da cidade pelas diferentes vivências da loucura. Assim, experiências locais de assistência constroem-se como dispositivos de base territorial, projetos de desinstitucionalização são implantados para proporcionar aos egressos de longas internações o retorno ao convívio na cidade e experiências de arte e cultura e economia solidária também ganham destaque nesse processo.

Quando nos referimos as noções de território e territorialidade, não estamos aludindo somente a articulação dos conceitos de distância, acessibilidade e tempo, o que é comumente trabalhado nas análises de distribuição de serviços de saúde. Estamos propondo uma noção de território que englobe os sentidos, os significados e as produções de relações de um determinado lugar. Esse território que é, ao mesmo tempo, físico e simbólico, está em constante construção e disputa, portanto, ao ocupar a cidade é necessário pensar que cidade queremos e é por isso que ao longo desse processo de RPB, necessitamos revisitar e (re)construir possibilidades ideais de cidade que possam funcionar como um elemento norteador.

Certamente há tantas maneiras de conceber cidade quanto há cidades ${ }^{25}$, mas então, como saber que cidade devemos construir no processo de $\mathrm{RPB}$ ? Ou por qual concepção ideal de cidade devemos lutar? Além de inúmeras, as concepções de cidade são disputadas pelos campos de saber que a concebem. A compreensão mais básica e acessível a todos nós pode ser encontrada no dicionário. Em uma busca em três dicionários diferentes - Aurélio, Michaelis e Priberam -, encontramos definições bem próximas, que enfatizam a existência de grande quantidade de pessoas e focam no fato dessas pessoas trabalharem em indústrias e serviços, em oposição ao que acontece no campo. Dessa forma, Ferreira ${ }^{26}$ define cidade como "complexo demográfico formado, social e economicamente, por uma importante concentração populacional não agrícola, dedicada a atividades de caráter mercantil, industrial, financeiro e cultural; urbe".
Mas a cidade nem sempre teve sua principal característica na aglomeração de pessoas e muito menos no seu potencial econômico e industrial. Na Grécia Antiga, por exemplo, o conceito de pólis implicava no fato de política e cidade se manterem ligadas, afinal esse era o espaço onde as pessoas conseguiam expressar uma unidade. Pagot $^{27}$ indica que foi a concepção romana de cidade que influenciou as urbanizações contemporâneas e não a concepção grega, já que a cidade romana criou a geometria do espaço não se baseando na união e sim na divisão.

Se enveredarmos para o campo da Geografia, esbarramos com a definição de Milton Santos, que considera que a “(...) cidade constituiu uma forma particular de organização do espaço, uma paisagem e, por outro lado, preside às relações de um espaço maior, em seu derredor, que é sua zona de influência"28 (p. 7). Já o geógrafo francês Pierre George traz um conceito de cidade que conversa com o tempo histórico e com a sociedade. Assim, a cidade seria ao mesmo tempo um acontecimento histórico e geográfico, onde sua forma representa o elo entre o passado e o presente $^{29}$. Henri Lefebvre, sociólogo francês de orientação marxista, ao falar de cidade, diz buscar na filosofia algo que os outros campos não são capazes de lhe dar: a totalidade da cidade. Pensando nessa totalidade ele afirma que

a cidade projeta no terreno uma sociedade, uma totalidade social ou uma sociedade considerada como totalidade, compreendida sua cultura, instituições, ética, valores, em resumo, suas superestruturas, incluindo sua base econômica e as relações sociais que constituem sua estrutura propriamente dita ${ }^{30}$. (p. 141)

Seguindo o pensamento de Lefebvre, se projetamos na cidade a nossa cultura e as nossas relações, isso nos diz que projetamos também na cidade as nossas segregações. Dessa maneira, mulheres, negras, negros, pessoas $\mathrm{LGBTQI}^{+}$, pobres, loucas e loucos e suas intersecções ocupam lugares à margem na cidade (metaforicamente $\mathrm{e}$ concretamente). Mesmo sabendo que esse não é o tema principal desse artigo, é mandatório que fique registrado que, historicamente, os grupos minoritários ocuparam mais os asilos, os manicômios e os hospitais psiquiátricos - e não esqueçamos das cadeias -, em uma ação perversa de enclausurar pelas vias do poder médico toda a sorte de indesejáveis à sociedade industrial burguesa. Barros et al. ${ }^{31}$, em um estudo sobre os moradores dos hospitais psiquiátricos de São Paulo, constataram que, em relação ao censo demográfico do estado, há uma maior proporção de ne- 
gros nos hospitais psiquiátricos por não terem renda e/ou lugar para morar. Isso constata que

a população negra sofre historicamente processos ininterruptos de abandono e apartamento social. O lugar por excelência do abandono e exclusão é o manicômio, assim como outras instituições totais. Os dados consolidados comprovaram que à população negra cabe a injusta posição de prioritária no ranking da exclusão social nos hospitais psiquiátricos do estado de São Paulo ${ }^{31}$ (p. 1240).

Assim, se a cidade reserva um lugar às suas margens para os excluídos, temos, desde a criação dos primeiros hospitais psiquiátricos, a distância dos grandes centros urbanos como uma condição. Era assim no Hospital de Bicêtre - dirigido por Philippe Pinel -, era assim no Hospício de Pedro II quando da sua criação. Se Sennett ${ }^{25}$ define cidade como "uma povoação humana onde é provável que desconhecidos se encontrem" (p. 39), esses modos de construção e planejamento das cidades modernas tentam promover o oposto. Dessa forma, cheia de muros, barreiras, divisões reais ou imaginárias, tornam-se cidades que não estão preparadas para os diferentes. ${ }^{2}$ Em seu livro mais recente, Construir e Habitar: ética para uma cidade aberta, Sennett ${ }^{32}$ discute a possibilidade de as construções promoverem mais encontros entre desconhecidos, no que ele chama de cidade aberta: uma cidade que é permeável, com espaços convidativos e que, em suma, inclui a diferença. Pensando no desafio de construir uma cidade que possa promover tais encontros, Sennett ${ }^{32}$ divide a cidade em duas: a cidade em sua forma construída, a ville, e a cidade em sua forma de experiência vivida, a cité. $\mathrm{O}$ autor chama atenção para a dualidade e a disputa dessas duas formas de cidade e, inclusive, lança um questionamento a si próprio, indagando se a resposta para criar uma cidade aberta seria dar mais poder aos cidadãos. Como diz McGuirk ${ }^{33}$ fica claro que

"Construir e habitar" é a tentativa de Sennett de responder a essa pergunta. E ele tem quase que um apego Taoista à harmonia e ao equilíbrio. Dê aos arquitetos e planejadores muito controle e a cité sofre; tenha muita fé nos cidadãos e a a ville definha. A cidade aberta que Sennett imagina é uma que requer que nós aceitemos a diferença, mesmo que nós não nos identifiquemos com ela.

A partir desse ideal de cidade de Sennett ${ }^{32}$, podemos pensar em uma cidade que é um ímã, ou seja, uma cidade que é "um campo magnético, que atrai, reúne e concentra os homens" 34 (p. 12), mas que, ao mesmo tempo, também é uma cidade que

(...) é fruto do trabalho coletivo de uma sociedade. Nela está materializada a história de um povo, suas relações sociais, politicas, econômicas e religiosas. Sua experiência ao longo do tempo é determinada pela necessidade humana de se agregar, de se inter-relacionar, de se organizar em torno do bem - estar comum; de produzir e trocar bens e serviços, de criar cultura e arte; de manifestar sentimentos e anseios que só se concretizam na diversidade que a vida urbana proporciona ${ }^{27}$. (p. 23)

Em suma, o que propomos é uma cidade que promova o encontro com o desconhecido, com o diferente, que o aceite, que seja uma construção coletiva, uma cidade que seja permeável. Acreditamos que a concepção de cidade aberta seja a que mais abraça todos esses ideais e por isso, propomos que adotemos essa cidade aberta como uma diretriz ao pensar em estratégias e políticas de saúde mental nas diferentes dimensões do processo de RPB. Pelo encontro. Por uma cidade aberta.

\section{Considerações finais: construindo a dimensão espacial da Reforma Psiquiátrica Brasileira}

Se conseguimos construir e apontar para a potencialidade das arquiteturas e dos espaços na produção de relações e subjetividades; se somos capazes de entender que as análises, as políticas e a implantação de estratégias devem discutir essa potencialidade; se conseguimos pensar em um ideal de cidade que nos ajudaria e orientaria tanto no campo prático quanto epistemológico de superação do paradigma manicomial, não seria interessante que essa discussão pudesse estar estruturada como uma ferramenta de análise? Como dar centralidade a essa discussão no processo de RPB?

Como já foi mencionado na introdução do artigo, entendemos a Reforma Psiquiátrica Brasileira enquanto um processo permanente e contínuo, pautado na mobilização social no que Rotelli et al. ${ }^{5}$ ao falar das reformas psiquiátricas, denomina de processo social complexo. Tal processo social complexo já foi analisado e categorizado por muitos teóricos do campo através de diferentes pontos e categorias de análise. Amarante $^{6,7}$, dentre autores influentes e importantes do campo, objetivando uma reflexão sistematizada sobre o processo de RPB, propõe analisa-lo através de dimensões. Afinal, “(...) um processo social complexo se constitui enquanto entrelaçamento de dimensões simultâneas, que ora se alimentam, ora são conflitantes; que produzem pulsações, paradoxos, contradições, consensos, tensões."7 (p. 63) 
Dessa forma, o autor propõe quatro dimensões essenciais: a teórico-conceitual ou epistemológica que, através da ruptura com os preceitos basilares da psiquiatria clássica e a visão biológica reducionista da história natural da doença, constrói o seu próprio campo teórico-conceitual que procura o diálogo entre os diferentes campos e disciplinas que estão relacionadas ao cuidado da loucura; a sociocultural que procura transformar o imaginário social da loucura construído historicamente, onde o louco ocupa uma posição desqualificada e, às vezes, é categorizado pelo estigma da periculosidade; a jurídico-política que procura construir novas pactuações de poder através da ação de protagonistas e diferentes atores desse processo que possam impulsionar e embasar, por meio da política e da esfera jurídica, uma transformação social; a técnico-assistencial que está relacionada com a prática e a teoria, ou seja, com a práxis, onde se propõe uma nova organização de serviços que possa promover rede de apoio, espaços de sociabilidade, geração de renda, moradia e produção de vida ${ }^{6,35}$. Ao que tudo aponta, a discussão dos espaços estaria mais conectada com esta última dimensão. Mesmo sabendo que as dimensões são dinâmicas e não estanques, acreditamos que esta dimensão e nem nenhuma outra consigam dar conta da centralidade necessária que a discussão dos espaços da loucura merece. Dito isto, propomos que pensemos em uma nova dimensão para discutir o processo de Reforma Psiquiátrica Brasileira: a dimensão espacial.

Essa dimensão abarca tudo o que discutimos ao longo desse artigo, portanto, para trabalhar a dimensão espacial da reforma é necessário entender a arquitetura como um campo de saber capaz de conceber espaços que produzem relações e subjetividades; a partir disso, é preciso pensar quais relações e subjetividades estamos tentando produzir e facilitar; é necessário entender que os espaços em si e suas arquiteturas físicas e concretas fazem parte de processos subjetivos e que por isso merecem atenção; que os espaços de cuidado em saúde mental devem ser pensado juntamente com o ideal de cidade que se pretende e tentar construir os dois de uma forma dialógico é essencial; que o território físico e simbólico devem ser levados em consideração; e que os espaços da loucura devem estar para além da construção de dispositivos de assistência em saúde mental, em uma lógica intersetorial e integral de saúde.

Assim, a dimensão espacial procura transformar o paradigma manicomial de cuidado em saúde mental através do rompimento com a centralidade dos espaços de cuidado estritamente de saúde e com as estruturas arquitetônicas manicomiais. É importante ressaltar, que para que a dimensão espacial se cumpra é necessário não só modificar as arquiteturas ou os espaços, mas sim, trabalhar as outras dimensões para que se rompa de fato o paradigma manicomial, evitando que se produzam práticas manicomiais em serviços substitutivos.

Tanto quanto há maneiras singulares e inúmeras de experienciar a loucura, há possibilidades múltiplas de construções de espaços de cuidado em saúde mental. Por isso, não podemos cair na armadilha de desejar um modelo de espaço construído predefinido e engessado por alguma lei ou política pública. Isso representaria o fim da criatividade e desrespeitaria os sentidos de cada território, onde o a experiência-loucura e os significados de assistência e cuidado são próprios daquele lugar. É claro que precisamos trabalhar melhor os parâmetros para o que definimos como dispositivos substitutivos e isso se faz urgente. Ainda mais na atualidade, momento em que os hospitais psiquiátricos voltam à Rede de Atenção Psicossocial e o conceito de serviço substitutivo vem sendo dirimido.

Mas por que introduzir uma nova dimensão se podemos debater e analisar as questões dos espaços de cuidado através das outras já propostas? Bom, além de poder debater com mais especificidades a questão, estaríamos dando ao espaço construído um lugar de destaque e chamando atenção para o campo da saúde mental e saúde coletiva de que esse é um fator fundamental no nosso processo de reforma. Fator esse que, muitas vezes, passa desapercebido ou que toma um lugar periférico nas discussões. E, então, quais são os desafios dessa dimensão? O maior desafio enfrentado por essa dimensão, sem dúvida, é a superação do paradigma manicomial-arquitetônico.

Se o processo da Reforma Psiquiátrica Brasileira é complexo e, portanto, vivo e dinâmico, também são as dimensões construídas e elegidas para sua análise. Dito isto, esperamos que essa discussão e aprofundamento da dimensão espacial não se encerre nesse artigo. Nós continuaremos a desenvolvê-la e almejamos que as articulações feitas aqui se desdobrem como um convite para que outros estudiosos se interessem e colaborem com a expansão dessa dimensão e, consequente, fortalecimento da luta antimanicomial. 


\section{Colaboradores}

L Paladino participou de todas as etapas da pesquisa. PDC Amarante participou da construção do argumento do artigo, análise e discussão da literatura, escrita e revisão do manuscrito.

\section{Financiamento}

O presente trabalho foi realizado com apoio da Coordenação de Aperfeiçoamento de Pessoal de Nível Superior - Brasil (CAPES) - Código de Financiamento 001.

\section{Referências}

1. Foucault M. História da loucura na idade clássica. São Paulo (SP): Perspectiva; 2012.

2. Venturini E. A Linha Curva: o espaço e o tempo da institucionalização. Rio de Janeiro: Fiocruz; 2016. 196 p.

3. Machado R, Loureiro A, Luz R, Muricy K. Danação da norma: a medicina social e constituição da psiquiatria no Brasil. Rio de Janeiro: Edições Graal; 1978. 559 p.

4. Paim JS. A reforma sanitária brasileira e o Sistema Único de Saúde: dialogando com hipóteses concorrentes. Physis 2008; 4(18):625-644.

5. Rotelli F, Leonardis O, Mauri D. Desinstitucionalização. São Paulo: Hucitec; 1990.

6. Amarante P. A (clínica) e a Reforma Psiquiátrica. In: Amarante P, organizador. Archivos de saúde mental e atenção psicossocial. Rio de Janeiro: Nau Editora; 2003. p. 45-66. (Coleção Archivos).

7. Amarante P. Saúde mental e atenção psicossocial. Editora Fiocruz; 2007. 120 p.

8. Goffman E. Manicômios, prisões e conventos. São Paulo: Perspectiva; 2015.

9. Cançado ML. Hospício é Deus: Diário 1. Rio de Janeiro: Record; 1979.

10. Sommer R. Espaço Pessoal: as bases contemporâneas de projetos e planejamentos. São Paulo: Editora da Universidade de São Paulo; 1973.220 p.

11. Barreto AHL. Diário do hospício; o cemitério dos vivos. Rio de Janeiro: Secretaria Municipal de Cultura, Departamento Geral de Documentação e Informação Cultural, Divisão de editoração; 1993. 224 p.

12. Barton R. Institutional Neurosis. Bristol: John Wright \& Sons Ltd.; 1966.

13. Basaglia F. As instituições da violência. In: Amarante $\mathrm{P}$, organizador. Escritos selecionados em saúde mental e reforma psiquiátrica. Rio de Janeiro: Garamond; 2010. p. 1-132.

14. Carvalho M. Ambiente construído e comportamento espacial na instituição psiquiátrica: questões éticas em Observação Participante. Saude Debate 2001; 25(58):48-56.

15. Carvalho M. A Poética da Casa: a tessitura dos espaços do habitar. In: Ferreira G, Fonsêca P, Boff L, organizadores. Conversando em casa. Rio de Janeiro, Brazil: 7 Letras; 2000. p. 119-128.

16. Carvalho M, Souza Cruz AB, Fávero M, Vias Boas N, Freire WV. O Corpo e os Espaços do Manicômio. In: Martins AM, Carvalho M, organizadores. Novas Visões: fundamentando o espaço arquitetônico e urbano. Rio de Janeiro: Booklink; 2001. p. 321-341.

17. Michelucci G. Lo spazio, una comunicazione interrotta. In: Tranchina P, organizador. Portolano di psicologia: esperienze prospettive convergenze di una professione giovane. 1. ed. Pistoia: Cooperativa Centro di documentazione; 1994. p. 57-59.

18. Foucault M. O Corpo Utópico, as Heterotopias. São Paulo: n-1 Edições; 2013.55 p.

19. Segaud M. Antropologia do Espaço: habitar, fundar, distribuir, transformar. São Paulo: Edições Sesc São Paulo; 2016.312 p.

20. Chuhurra OL. El espacio. In: Estética de los Elementos Plásticos. Editora Labor S.A; 1971. p. 61-88.

21. Costa L. Registro de uma vivência. São Paulo: Empresa das Artes; 1995. 
22. Foucault M. História da sexualidade I: a vontade de saber. Rio de Janeiro: Graal; 1999. 149 p.

23. Vieceli AP. Lugares da Loucura: arquitetura e cidade no encontro com a diferença. Porto Alegre: UFRGS; 2014.

24. Engel M. Os delírios da razão: médicos, loucos e hospícios, Rio de Janeiro, 1830-1930. Rio de Janeiro: Editora Fiocruz; 2001.351 p. (Loucura \& civilização).

25. Sennett R. The Fall of Public Man. New York: Penguin Books; 1977.390 p.

26. Ferreira $\mathrm{AB}$ de H. Dicionário Aurélio da Língua Portugues. Curitiba: Editora Positivo; 2014.

27. Pagot AM. O louco, a rua, a comunidade: as relações da cidade com a loucura em situação de rua. Rio de Janeiro: Editora Fiocruz; 2012. $230 \mathrm{p}$

28. Santos M. A cidade como centro de região. Salvador: Livraria Progresso Editora; 1959.

29. Vasconcelos PA. A cidade, o Urbano, o Lugar. Geousp 1999; (6):11-16.

30. Lefebvre H. De lo rural a lo urbano. Barcelona: Ediciones Península; 1978.

31. Barros S, Batista LE, Dellosi ME, Escuder MML. Censo psicossocial dos moradores em hospitais psiquiátricos do estado de São Paulo: um olhar sob a perspectiva racial. Saude Sociedade 2014; 23(4):1235-1247.

32. Sennett R. Building and dwelling: ethics for the city. New York: Farrar, Straus and Giroux; 2018.

33. McGuirk J. Can cities make us better citizens? [Internet]. The New Yorker. 2018 [cited 2018 dez 12]. Available from: https://www.newyorker.com/books/pageturner/can-cities-make-us-better-citizens

34. Rolnik R. O que é cidade. São Paulo: Brasiliense; 2009.

35. Yasui S. Rupturas e encontros: desafios da Reforma Psiquiátrica Brasileira. Rio de Janeiro: Escola Nacional de Saúde Pública Sergio Arouca; 2006.

Artigo apresentado em 31/10/2020

Aprovado em 16/10/2021

Versão final apresentada em 18/10/2021

Editores-chefes: Romeu Gomes, Antônio Augusto Moura da Silva 